\title{
Formulating Expectations for Future Water Availability through Infrastructure Development Decisions in Arid Regions
}

\author{
Afreen Siddiqi ${ }^{1,2}$, Farah Ereiqat ${ }^{3}$, and Laura Diaz Anadon ${ }^{2,4}$ \\ ${ }^{1}$ Engineering Systems Division, Massachusetts Institute of Technology, Cambridge, MA 02139, USA \\ ${ }^{2}$ John F. Kennedy School of Government, Harvard University, MA 02138, USA \\ ${ }^{3}$ Graduate School of Design, Harvard University, MA 02138, USA \\ ${ }^{4}$ Department of Science, Technology, Engineering \& Public Policy, University College London, UK
}

\begin{abstract}
Water resources development options are usually selected on a least-cost basis. While economic considerations are dominant in choosing projects, there are also a mix of other factors including social demands, political viability, social equity, and environmental considerations that impact final decisions and development of water supply systems. Understanding local priorities in water resource management decisions can allow for forming expectations of future regional water availability through new infrastructure projects. In this research, we propose that future human mediated water availability in arid regions may be assessed by considering key projects that have been identified or proposed by regional experts and organizations. Using Multi-Criteria Decision Methods as a framework to organize a set of decision criteria and their relative salience, the likelihood of selection (and development) of a project can be determined and used to form expectations of future regional water availability. We apply this approach in a case study of Jordan, and find that large-scale desalination projects - that have been in the planning books for decades are now most likely to be pursued and implemented in the country. Finally, we discuss strengths, limitations, and the general applicability of this method for assessing future water availability in other arid regions.
\end{abstract}

Keywords-multi-criteria decision analysis; decision theory; water supply planning; water management; infrastructure development

\section{INTRODUCTION}

Demands for fresh water continue to grow with increasing population, and competition across different economic sectors has intensified for this constrained resource [Falkenmark. 2008; Gleick, 2009]. Public sector planners as well as private sector developers, making investment decisions for infrastructure expected to function for decades into the future increasingly need to assess mid-term and long-term water availability. In general, it is difficult to make future assessments of availability through the construction of new infrastructure projects, and we cannot fully rely on historical trends for forecasting. Despite the challenges, developing methods that can allow for forming reasoned expectations can help inform decisions of those that may be affected by future developments in water-related infrastructure. 
In this work, we approach the question of estimating future availability by analyzing projects under consideration by regional planners, and assessing the likelihood of their implementation and the consequent impact on local water supply. As previously mentioned, we consider 'availability' as water supply that is controlled by decision makers and engineered projects - we are not modeling water resources from a hydrogeological standpoint, or the natural hydro-climatic system of a region.

In order to assess the likelihood of implementation of projects, we follow a quantitative and qualitative empirical methodology in which we determine criteria employed by key decision-makers, and use that information to form an assessment of which projects are likely to be chosen. We use Multi-Criteria Decision Methods (MCDM) to elicit and encode decision factors and their relative importance, and then analyze the full combinatorial set of options and preferences to quantify likelihood of implementation of future projects. This approach allows the identification of likely regional infrastructure development trajectories and consequent water supply volume that would become available over time.

\section{BACKGROUND AND LITERATURE REVIEW}

A variety of Multi-Criteria Decision Methods (MCDM) have been developed and used in water resources planning [Loken, 2007]. The methodologies range from simple scoring techniques to compare multiple alternatives to multi-objective optimization methods that include goal programming, compromise programming, and stochastic optimization. In water sector planning, the methods have been applied in resource management [Geng, 2013], channel improvements [Chowdhury, 2008], long distance water transfer projects [Abrishamchi, 2005], and desalination project evaluations [Akash, 1997; Jaber, 2001] among others.

There are two broad categories within MCDM that have been applied in water resources planning. The first involves discrete decision spaces (i.e. a set of discrete alternatives) in which the best option is to be determined given a set of criteria, and the other relates to resource allocation problems (e.g. allocating water volume among competing users) to optimize a set of objectives. In most of the studies focused on discrete alternatives evaluation, researchers have used expert and/or stakeholder interviews to determine weights for decision criteria that include economic, social, public health, technical and sustainability factors [Chowdhury, 2008; Akash, 1997; Jaber, 2001; Lai, 2008; Ramanathan, 1995]. Additive weighted sum methods have been developed and used to identify best options [Thuesen and Fabrycky, 2001]. A key limitation of these methods, however, is the subjectivity, and a decision maker's judgment influences the outcome for the 'best' identified alternative. Despite this limitation, these approaches are used in practice. Some form of sensitivity analysis is often conducted to determine the impact of changing the values of the criteria and weighting coefficients to assess the robustness of the optimal result.

In other approaches in decision analysis where multiple decision criteria are involved, an Even Swap Method has been developed in which the performance of the alternatives on a set of different criteria is adjusted in a consistent way such that a combined and meaningful value is achieved and a single indicator of net equivalent value is obtained for each alternative [Hammond, Keeney, and Raiffa, 1999]. For instance, as a simple example, consider a case where several projects are to be evaluated on the criteria of cost (in billion dollars) and environmental impact (categorized from low to high). While it may not be possible to fully monetize the environmental impact (and thereby get a gross cost metric), it may be possible to evaluate the cost of changing the environmental impact level from one category to the next category for each alternative. In that case, the environmental impact categories are then 'swapped' to be at the same consistent level (say 'low' category) and the associated cost adjustments are made for each alternative to switch to that category of environmental impact. The decision evaluation can now be made on the adjusted cost criteria as 
the performance on the environmental impact for all alternatives has been made equivalent (to a 'low' category level). The even swap method allows for avoiding pitfalls that can come about due to numerical aspects of assigning quantitative values to categorical variables, and allows for sharpening the decision space. However, it can be challenging to obtain data that allows for making the even swaps among the alternatives, and in many cases the even swaps have to be made on a subjective basis.

In this work, we identify the composition and salience of different decision factors by interviewing decision makers in the water resource development sector within a region. We then use the relative performance of projects under consideration for development on the set of identified factors to form expectations of future supply. In other words, we use MCDM as an organizing framework to form expectations of future development decisions by using expected project performance as a proxy of likelihood of project selection. In traditional analysis, MCDM is employed to select a best alternative from a given set of options. In our work, we do not perform an optimization, or select an optimal solution; rather we use MCDM to create a traceable and systematic basis for forming expectations for the future. Our focus is prospective, rather than prescriptive in nature. Furthermore, our approach does not require making judgments about weights by proposing a probabilistic approach to investigate the robustness of different projects to the full spectrum of weights. To the best of our knowledge, MCDM has not been previously employed in this manner, and our work develops a new approach. Our case study is based on real projects (as opposed to hypothetical options) and we compare our results with actual decisions that have been made to identify the strengths and limitations of our approach.

\section{METHODOLOGY AND APPROACH}

We base our methodology on a series of assumptions: we assume that resource development is through a discrete set of infrastructure projects. Typically, resource availability is managed through supply augmentation as well as demand management. We propose that demand management schemes can also be represented as 'projects' with associated costs and impacts on water volume that becomes available in the system for use as a result of demand management measures.

We also assume that the resource will be needed for direct use and cannot be substituted through trade and imports. The concept of virtual water, and embedded water in imported goods has been extensively studied for understanding how trade helps alleviate water demands and local supply shortages [Dalin et al. 2012]. We do not consider these aspects in our analysis. Additionally, we assume that a few key actors ultimately drive decisions that lead to implementation of projects, and that decisions are based on a discrete set of factors that collectively shape final choices.

Starting with these assumptions, we formulate the following steps:

1. Identify the decision-makers (DMs) and the decision space - i.e. set of projects being considered for development. This step involves stakeholder analysis for identification of key institutions, organizations, and actors who are involved in planning.

2. Using results of the stakeholders analysis, conduct discussions and surveys to determine decision criteria, and their relative importance as viewed by key decision makers. This information will typically be collected through interviews and complemented with reports and the academic literature.

3. Organize data of the projects and their performance on decision criteria (factors) in a performance matrix, and compare projects (alternatives) using techniques such as normalized additive weighting. 
4. Compare results of analysis with past decisions (as represented by implemented and commissioned projects). This can be done by using data of projects that have been implemented, and checking how the results of the analysis match with actual decisions (and development).

5. Assess likelihood of future project selection by evaluating performance on different preference (weights) sets, and conduct a stochastic evaluation in which probabilities of importance of different criteria are varied. The results can be further analyzed to determine factors that may drive selection of particular projects in the future as well as the conditions that would lead to new salience of those factors. This allows for obtaining insights on what future scenarios may drive progression along possible different development pathways.

The details of the approach we used are as follows:

Suppose $n$ projects are being considered for development. A set of $m$ criteria is employed by decision makers for evaluating these projects. An $m \times n$ performance matrix, $A$ is then defined as:

$$
A=\left[a_{i k}\right]
$$

where $a_{i k}$ is the value (or performance) of $k^{\text {th }}$ project (or alternative) for $i^{\text {th }}$ criterion.

The performance across each criterion is normalized, and an $m \times n$ matrix, $\bar{A}$ is obtained. For criteria for which performance is desired to be minimized (such as cost), $\overline{a_{i k}}$ is given as:

$$
\bar{a}_{i k}=\frac{\left[\max \left(a_{i}\right)-a_{i k}\right]}{\left[\max \left(a_{i}\right)-\min \left(a_{i}\right)\right]}
$$

where $\max \left(a_{i}\right)$ denotes maximum value for $i^{\text {th }}$ criteria, $\min \left(a_{i}\right)$ denotes minimum value for $i^{\text {th }}$ criteria across all $k$ (i.e. set of projects). For criteria for which performance is desired to be maximized (such as supply volume), the $\overline{a_{i k}}$ is given as:

$$
\bar{a}_{i k}=\frac{\left[a_{i k}-\min \left(a_{i}\right)\right]}{\left[\max \left(a_{i}\right)-\min \left(a_{i}\right)\right]}
$$

A weighted, normalized vector $\boldsymbol{J}$ is now defined as:

$$
J_{[1 \times n]}=\mathrm{w}_{[1 \times \mathrm{m}]} \bar{A}_{[m \times n]}
$$

where $\mathrm{w}=\left[\begin{array}{lll}w_{1} & \mathrm{~L} & w_{m}\end{array}\right]$, with $w_{\mathrm{i}}$ a weighting factor of $i^{\text {th }}$ criterion and

$$
\sum_{i=1}^{m} w_{i}=1
$$

Note that $\boldsymbol{J}$ is a row vector, and consists of weighted, normalized performance values of the $n$ projects.

We next explore the combinatorial space for $\mathbf{w}$ where $w_{i}$ are systematically varied from 0 to 1 with step $d w$, and selecting sets of $\mathbf{w}$ where Eq. 5 holds. For $q$ such combinations of $\mathbf{w}$, we determine number of cases when the $i^{\text {th }}$ project is determined to be $i^{*}$, where

$$
i^{*}=\arg \max (J)
$$

i.e. the project with highest normalized weighted performance.

If $i^{\text {th }}$ project is determined to be $i^{*}$ in $r$ cases (of the $q$ possible combinations of $\mathbf{w}$ ), we consider the likelihood of project $i$ being selected and developed as: 


$$
\pi_{i}=\frac{r}{q} .
$$

Thus, if project $i$ has associated annual supply volume $v_{\mathrm{i}}$, then there is $\pi_{i}$ likelihood of $v_{i}$ being added to regional water availability.

Eq. 7 applies when all possible (and valid) combinations of $\mathbf{w}$ are equally likely to occur. In reality, certain values for $\mathbf{w}$ (that reflect particular priorities of local decision makers) should be more carefully studied, perhaps using non-uniform probability distribution functions, and it should be considered that the priorities could change based on local political, economic, and social issues.

We can describe this problem with the decision tree in Fig. 1. The branches emanating from the decision node represent options (projects) being considered. The diagram shows that for each of the $n$ projects being considered for development decision, there is a chance that various scenarios that change the context of project selection decisions may occur, wherein a particular set of decision preferences will hold. The particular set of preferences $\left(\mathbf{w}_{\mathrm{k}}\right)$ will impact the performance of a given project (i.e. its $j$ is a function of $\left.\mathbf{w}_{\mathrm{k}}\right)$.

We define a matrix $W$, with $s$ rows where each row constitutes a scenario, a vector $\mathbf{w}$ with values representing scenarios with different decision priorities:

$$
W=\left[\begin{array}{ccc}
w_{11} & \mathrm{~L} & w_{1 m} \\
\mathrm{M} & & \mathrm{M} \\
w_{s 1} & \mathrm{~L} & w_{s m}
\end{array}\right\rfloor .
$$

If the $k^{\text {th }}$ scenario has probability $p_{k}$ of occurring, and vector $\mathbf{p}$ is defined as: $p=\left[\begin{array}{lllll}p_{1} & \mathrm{~L} & p_{k} & \mathrm{~L} & p_{s}\end{array}\right]$, where

Fig. 1. Decision Tree Representation of project planning under scenarios leading to different preferences.

$$
\sum_{k=1}^{s} p_{k}=1
$$

Then the expected performance is given by:

$$
\bar{J}_{[1 \times n]}=\mathrm{p}_{[1 \times s]} W_{[s \times m]} \bar{A}_{[m \times n]}
$$

The $i^{\text {th }}$ element of $\overline{\mathrm{I}}, \bar{j}_{i}$, is the expected performance of project $i$, given the probability distribution $\mathbf{p}$ and set of decision priorities W. The project $i^{*}$ will likely be selected where $i^{*}=\arg \max (J)$.

IV. APPLICATION: AsSESSING FUtURe WATER AVAILABILITY IN JORDAN 
Jordan is a water scarce country, with annual per capita water resources of $145 \mathrm{~m}^{3}$ that are well below the scarcity threshold of $1000 \mathrm{~m}^{3}$ [JWS, 2008]. The water resources in Jordan have been extensively studied, and a number of studies have employed MCDM to evaluate supply augmentation options (including desalination, long distance pumped groundwater pipelines), and demand management options (such as changing cropping patterns in the agricultural sector) [Akash, 1997; Jaber, 2001; Al-Zu’bi, 2003].

In one study, stochastic linear programming was used to plan for water supply in the capital city, Amman (host to $40 \%$ of the country's population), under different climate change scenarios. The results recommended delaying use of water from the Disi aquifer (a trans-boundary non-renewable aquifer on the border of Jordan and Saudi Arabia) until 2060 and beginning to use desalinated water from the Red Sea in 2085 [Ray, 2014]. In another study, using stochastic mixed integer optimization, a systematic evaluation of both conservation actions with new supply or loss reduction alternatives for residential and commercial water use was conducted [Rosenberg, 2009]. The results showed that megaprojects such as the Red-Dead canal (in which water from the Red Sea is conveyed to the Dead Sea) are not ideal given the availability of cheaper alternatives such as a reduction of leakages in water delivery networks.

While Jordan's natural water resources and infrastructure options are well understood [Hadadin, 2010], recent political crises, infrastructure development for harnessing local energy resources, and longer-term climate change projections lend increased importance to the question of understanding future water availability and access in the region. The political un-rest in neighboring countries has caused a large refugee migration that has burdened water supplies [Al-Zu'bi, 2003], plans for exploiting local oil-shale reserves require water for mining [MSES, 2007; MEMR, 2011], and climate change projections indicate further worsening of fresh water availability in the country. Since many decisions of critical infrastructure in urban and industrial development are inter-dependent [Alfaris et al., 2010], public and private planners and investors need and value information regarding access to important resources such as of water and energy.

Within this context we conducted a study assessing future water availability in the country, using the methodology described in section III. We first performed a detailed assessment of the stakeholders in the water sector in Jordan, and conducted more than 30 interviews across a range of stakeholder groups from highest-ranking decision makers (ministers and secretary generals) to rural community users and farmers. Table 1 provides a summary of the organizations and actors who where interviewed in two field trips to the country in 2012 and 2013.

\section{TABLE I. STAKEHOLDERS IN JORDAN WATER SECTOR}

A detailed description of the stakeholders analysis, based on interviews of the first field trip conducted in 2012, is provided in [Siddiqi, Kajenthira, Anadon, 2013]. One of the results of the interviews in 2012 was a compilation of an initial set of decision criteria based on discussions with a broad range of stakeholders. The criteria identified were cost (total cost over the lifecycle), annual supply (volume of water supplied by the project per year), foreign investment potential (likelihood of international funding agencies, international donors, or private investors providing financial support), environmental impact, and political feasibility. These factors are typical in case of water resources projects, although factors such as foreign investment potential may not always apply in different regions. As noted earlier, while cost is a dominant consideration [19], socio-political factors are also important (and can even trump cost considerations) given the unique and critical role of water for human needs.

Based on the initial interviews, we conducted a second round of targeted interviews in 2013 that included discussions with five important decision makers (DM) who filled a survey regarding set of criteria they 
consider in evaluating water supply projects. The DMs were provided with an initial set of criteria, and were asked to include their own factors or remove factors to formulate a list that would best describe a set of criteria that impact water sector planning in the country. The DMs also ranked the criteria in terms of importance. The results are shown in Table 2 .

TABLE II. LIST OF DECISION CRITERIA AND RANKS PROVIDED BY DECISION MAKERS IN JORDAN WATER SECTOR

Table 2 shows that cost was consistently one of the top two driving factors listed by the respondents. Most DMs added their own factors that included 'geographic distribution' (as a proxy for access equity), 'sectoral / social priorities', and 'sustainability of supply'. In Jordan, where some water resources are non-renewable, the sustainability of the supply source (in terms of annual renewable water supply) is an important issue.

In the next step, we identified the decision space by compiling information regarding major water infrastructure projects under consideration using reports of several agencies [JWS, 2008], and included only large-scale projects that are likely to have the greatest impact on total water availability in the country (see Table III). These projects collectively have the largest impact on water supply volume. The list in Table III is not exhaustive for all national projects, and there are a number of small-scale community level projects under development that improve water supplies by reducing leakage, or increase ground water pumping. In future work, the results can be further refined, however, we considered this set of large projects sufficient for the purpose of this analysis and to demonstrate the applicability of the method.

\section{TABLE III. WATER SUPPLY PROJECTS IN JORDAN}

An initial performance matrix for the set of projects and a set of criteria (that was derived through our survey) was then created. The cost and supply volume data was obtained from published literature and communication with Ministry of Water and Irrigation, while the values for categorical variables are our best estimates based on discussions during interviews and published literature. We note that the cost and supply volume data may vary for these projects based on different information sources. However, we found the variations to be within $\sim 10 \%$, and we therefore conducted the analysis using the data of Table IV to illustrate the method.

We combined the factors of 'sectoral/social priority' and 'geographic distribution' into the 'political feasibility' factor and 'sustainability of supply' into 'environmental sustainability' factor (and modified the definitions of these factors to include these additional considerations). The populated matrix is shown in Table 4.

\section{TABLE IV. DECISION CRITERIA FOR WATER SUPPLY PROJECTS IN JORDAN}

Traditionally, water sector projects have been developed on a least-cost basis [Haimes, 1977]. Our discussion and surveys also confirmed the importance of this factor. We therefore, first plotted a cost versus supply curve for all combinations of the projects to analyze how it compared with current development (see Fig. 2). Of the five projects considered in our set, two have already been implemented: the Waste Water Treatment and Expansion (WWTE) project, and the Disi Aquifer Pipeline (DAP) that was recently completed and commissioned [Namrouqa, 2013]. 
Fig. 2. Least-Cost Development (Pareto Front) for Water Supply Projects.

We find that the developed projects, WWTE (A5) and DAP (A4), lie on the pareto-curve (cost efficient frontier) of the decision space. Currently, the water supply system is in a state that consists of a combination of A5 and A4 (and is labeled as A5+A4 on the figure). In the future, the next possible states (in which three or four projects constitute the water supply system) can be E1 (A5+A4+A3), E3 (A5+A4+A2) or E5 $(\mathrm{A} 5+\mathrm{A} 4+\mathrm{A} 3+\mathrm{A} 2)$ that lie on the pareto frontier.

If the curve is strictly followed in the future, then the new project (in case of E1) is A3 (the Aqaba Desalination project) or (in case of E3) is A2 (the Jordan Red Sea Water Project). It should be noted that both of these projects are moving forward - and a major political agreement was recently made for the Jordan Red Sea Water Project [Kershner, 2013]. It is interesting to note that the desalination projects, and especially the Red-Dead Canal project has been in planning documents for decades, however other options were developed first since they were more cost effective. Since the lower cost options have been built, desalination projects are now being pursued. In case of the Red-Dead Canal project in particular, the plans have been drawn up with varying objectives (of water supply, hydropower, and replenishment of the Dead Sea) for over 150 years [Kristina, 2014].

Next, using data from Table IV, the matrix A was compiled and the corresponding $\bar{A}$ was computed using Eq. 1 - 3. We quantified the categorical variables with numbers 1, 3, and 9 for categories Low, Medium, and High. A full-factorial combinatorial set of values of $w_{i}$ (of $\mathbf{w}$ vector) was enumerated. For the set of five criteria $(m=5)$, and $d w=0.05$, a total of 9113 valid values of $\mathbf{w}$ (where Eq. 5 was satisfied) were used to evaluate the performance. In each case, $i^{*}$ (project with maximum performance) was determined, and for each project Eq. 7 was used to quantify likelihood of project selection. Fig. 3 shows the fraction of cases ( $\pi_{1}$ ) for each projects when it was chosen as $i^{*}$ (i.e. had highest performance).

\section{Fig. 3. Fraction of cases when a project performed best (as compared to other alternatives).}

The results show that in case of a choice between the five projects, WWTE had a probability of selection, $p_{i}$, of $83.1 \%$ (with $r=7573$ and $q=9113)$, DAP had $9 \%(r=850)$, and RDC had $7.9 \%(r=721)$. This result compares well with actual decisions, where WWTE has been implemented.

The insets in Fig. 3 show the cases for four projects (excluding WWTE), and three projects (excluding WWTE and DAP). In the four projects cases (the situation when WWTE has been implemented and remaining options are evaluated), the likelihood for DAP project is determined to be highest at $46 \%$ while $\mathrm{AD}, \mathrm{RDC}$, and JRSP have $32 \%, 18 \%, 4 \%$ respectively. In comparing with actual decisions, DAP has been recently implemented in 2013 [Namrouqa, 2013].

In the lower inset of Fig. 3 (with case of three projects, wherein WWTE and DAP are assumed to have been implemented), the highest likelihood is for JRSP from among the three alternatives of AD, RDC, and JRSP. Recent agreements between Jordan, Israel and Palestinian Authority show that plans for JRSP are advancing, and it seems highly likely to be implemented [Kershner, 2013] although there are continuing challenges and the development outcome is not fully certain [Kristen, 2014]. The completion of JRSP will add 120 million cubic meters of fresh water supply for Jordan.

The analysis shows (although with limited data) that the MCDM based results have good agreement with actual decisions. It is interesting to note, that if the pareto front of the cost-supply curve is strictly followed, 
the next project should have been the Aqaba Desalination plant (E1 in Fig. 2). In reality, the JRSP is advancing (E3 in Fig. 2), and the MCDM based assessment provides better indication of project selection (than simple cost considerations alone).

In comparing recommendations of various published studies with actual decisions (as represented by commissioned projects), we find that optimal solutions - determined by sophisticated optimization techniques - may not be realized. For instance, in one case the recommendation of a recent study was to delay the Disi Pipeline [Ray, 2012], in reality the pipeline has been commissioned. This indicates a difference in local decision priorities that actually shape outcome versus a theoretical set of objectives. The method presented here attempts to overcome the shortcomings of traditional optimization approaches and attempts to partly capture the reality of infrastructure development decisions.

Based on the associated water supply volumes for the projects, and their likelihood of selection, one can plot the cumulative distribution function (CDF) for new water supply volume that can be expected to become available. Figure 4 shows such a CDF for this case wherein a selection for DAP, AD, RDC, and JRSP is to be made (corresponding to the upper inset of Figure 3). The CDF charts (such as shown in Figure 4) can thus be employed to formulate assessments of future water availability in a region.

Figure 4. Cumulative distribution function for new water supply volume that can be expected to be available given likelihood of development of specific water infrastructure projects

For more comprehensive analysis, it is important to consider cases when decision preferences may shift. Given the difficulty estimating the probability vector $\mathbf{p}$ of different scenarios related to population growth, increased migration, future reductions in water availability, etc., we constructed a $W$ matrix (see Eq. 8), with scenarios motivated by decision factor rankings provided by the different DMs. In the first scenario, the rank ordering of factors was supply, cost, political feasibility, and foreign investment potential and so on (see Table II). We constructed $W$ such that the values of $w_{i j}$ reflected the rank ordering of the factors. For instance, for the rank ordering given by DM1 (which we used to define scenario 1), the following condition was imposed:

$$
w_{12}>w_{11}>w_{13}>w_{14}>w_{15} \quad(11)
$$

where row index corresponds to scenario number, and column index corresponds to criteria number (shown in Table IV). In each scenario, Eq. 5 was also satisfied. Fig. 5 shows some sample cases for w. Note that there are many sets of values of $\mathbf{w}$ that satisfy the criteria rank ordering (as shown in Eq. 11 for DM1).

Fig. 5a Left: Ensemble of weights for DM1 (criteria in order of importance is Supply, Cost, Political Feasibility, Foreign Investment Potential). Fig. $5 b$ Right- Ensemble of weights for DM4 (criteria in order of importance is cost, foreign investment potential, annual supply, political feasibility and environmental sustainability).

We computed the performance $\bar{J}$ for different values of $\mathbf{p}$, and results are shown for four cases in Fig. 6 (with particular instantiations of $\mathbf{w}$ ). We considered four cases since the rank of criteria by DM4 and DM5 were the same after aggregating the seven factors listed by DM5 into 5 factors as discussed earlier (see Table II). The colors in the sub-plots in Fig. 6 indicate variation in the results: RDC has highest expected 
performance in the gray plot, $\mathrm{AD}$ has highest expected performance in the dark blue colored plots, and JRSP has highest expected performance in the light blue colored plots.

Fig. 6 Expected performance where of projects under different scenarios of decision preferences. $\bar{J}$ is denoted at EJ on the y-axes.

In the first case where RDC is highest, inspection of Table II and Table IV shows that this is due to supply volume being the most important factor and this project provides the greatest supply volume as compared to other options. The expected performance of JRSP (a project that has recently undergone approval for development) is highest in fourth case (that corresponds to decision preferences provided by DM4 and DM5). The results clearly show that while case 4 matches best with current decisions, a shift in preferences can lead to different development decisions.

\section{DISCUSSION AND FUTURE WORK}

Water accessibility across different economic sectors of a region is defined by complex interactions of hydrological, economic, social, political and environmental factors. In this work we have focused on analyzing planned projects as a means of assessing mid-term ( $\sim 5$ to 10 years) availability provided through supply infrastructure development. We consider the question that given water supply possibilities (through a discrete set of projects), and knowing the decision criteria that are employed in a region, what projects are likely to be selected? The likelihood of selection of a project can be used to form an assessment of new supplies.

While the approach described in this paper offers many advantages, we also note its limitations. First, in our analysis we use a small sample survey - and recognize that it cannot provide full and comprehensive data. However, in the case of public sector infrastructure projects, understanding the basis used by key decision makers can provide important insights. We also note that causality may not be interpreted from implemented projects - and implemented decisions cannot be the only basis for verifying underlying decision factors. This approach does not guarantee finding a unique set of criteria and their relative importance, however, we were able to provide some confirmation of the influence of decision factors as provided by decision makers on future projects.

Another key limitation is that of accurately populating the performance matrix. It is often difficult to find reliable data. Furthermore, conducting thorough stakeholder analysis is challenging and it may not always be possible to interview key decision makers. We also note that it is possible for the criteria set to change or their relative importance to shift over time. Such changes can at times radically shift development pathways due to new and urgent priorities. A relevant example is Jordan's Red-Dead Canal Project where the driving factors have shifted over time from population growth, politics, economics, and more recently natural resource needs where replenishment of the fast depleting Dead Sea has provided new urgency and interest in developing this project [Kristen, 2014].

In future work, we will extend the analysis methodologically by incorporating and further building on the even swaps approach [Hammond, Keeney, and Raiffa, 1999] recognizing that weights may be easy to understand conceptually but do not accurately capture how people make real decisions. Furthermore, 
preferences are not linear, and non-linear desirability (or utility) curves for decision-makers can allow for improved characterization and decision analysis.

We will also conduct a broader assessment of impact of variation in the criteria set and their importance on the outcomes. For instance, in some cases criteria of energy consumption (where there has been significant increases for urban and agricultural water supplies [Siddiqi and de Weck, 2013; Siddiqi and Wescoat, 2013]) reliability of supply, water quality, and other factors may feature prominently. We will systematically consider the impact of sudden unforeseen shocks, crises, or disruptive changes that bring about important, large-scale shifts, through a more detailed analysis linking different scenarios and changes in the decision-making weights. Furthermore, we will expand the application of this method to other countries in the region to further test and refine the methodology as well as to assess future water availability in those regions.

Notwithstanding the above-mentioned limitations and future work, this approach offers a simple yet useful and traceable way for forming expectations without subjective input. In arid regions, where there are few water supply options, the key real options are typically well known, and documented. It is unlikely that entirely new large-scale projects get conceptualized, garner political support and necessary funds, and get implemented in a short span of time. There is usually a good sense of feasible projects for the mid-term time horizon that analysts can use for applying this methodology for meaningful results.

\section{ACKNOWLEDGMENT}

The authors thank Jade Salhab for assistance in organizing field interviews in Jordan. This work was supported by a research grant funded by BP in the Energy Technology Innovation Policy research group at John F. Kennedy School of Government, Harvard University. The findings, opinions, and conclusions expressed in this paper are those of the authors and do not necessarily reflect the views of the funding organization.

\section{Nomenclature:}

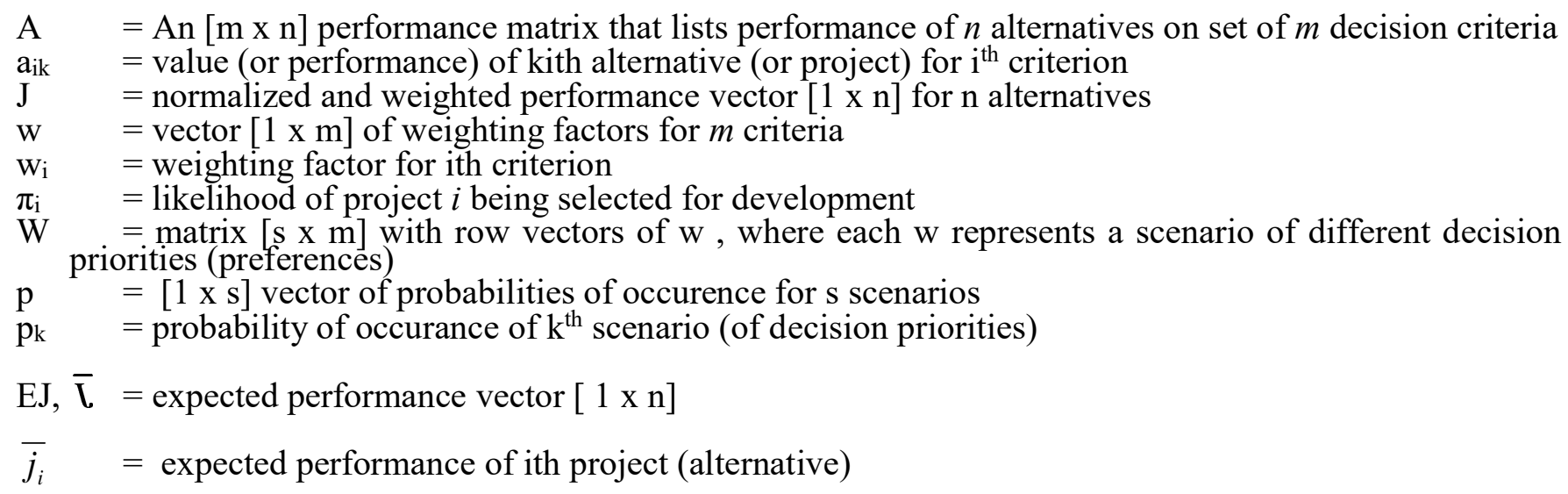

\section{REFERENCES}


Abrishamchi, A. "Case stụdy: application of multicriteria decision making to urban water supply." Journal of Water Resources Planning and Management. pp. 326-335, 2005

Akash, ,B. "Multi-criteria analysis of non-conventional energy technologies for water desalination in Jordan." Desalination., vol. 114 1997, pp 1-12.

Alfaris, A., Siddiqi, A., Rizk, C., and de Weck, O., "Hierarchical Decomposition and Multidomain Formulation for the Design of Complex Sustainble Systems." Journal of Mechanical Design, vol. 132 (9), 2010, 091003 (13 pages)

Al-Zu'bi, Y. "Multicriteria analysis for water productivity in the Jordan Valley." Water International, vol. 28, 2003, pp. 501-511.

Chowdhury, R. "Multicriteria decision analysis in water resources management: the malnichara channel improvement." Environment Science and Technology, vol. 5, 2008, pp. 195-204.

Dalin, C., Konar, M., Hanasaki, N., Rinaldo, A., and Rodriguez-Itrube, I. "Evolution of the global virtual water trade network", Proceedings of the National Academy of Sciences, 2012, vol. 109, pp. 5989-5994

Falkenmark, M. a. M., D. "Wake up to realities of river basin closure", International Journal of Water Resources Development, vol. 24, no. 2, 2008, pp. 201-215.

Geng, G. "Application of multi-criterion decision making analysis to integrated water resources management." Water Resources Management, 2013, pp. 3191-3207.

Gleick,P. Editor, The World's Water Vol 7. (2009)

Hadadin, N. "Water shortage in Jordan - sustainable solutions.” Desalination, vol. 250, 2010, pp. 197-202.

Hammond, J. S., Keeney, R. L., and Raiffa, H. Smart Choices, Harvard Business School Press, 1999.

Haimes, Y. Y. Hierarchical Analyses of Water Resources Systems: Modeling and Optimization of LargeScale Systems, McGraw-Hill International Book Company, 1977

Jaber $\mathrm{J}_{\dot{0}}$ "Evaluation of non-conventional water resources supply in Jordan." Desalination, vol. 136, 2001, pp. 83்-9ं2.

JWS. Water for Life: Jordan's Water Strategy 2008-2022, 2008.

Kershner, I., "A Rare Middle East Agreement, on Water", in the New York Times, December 9, 2013.

Kristina D., "The Read Sea-Dead Sea Project Update", Water Brief 2. in The World's Water, Vol 8, 2014, pp 153-158.

Lai, E. "Review of multi-criteria decision aid for integrated sustainability assessment of urban water systems", Urban Water Journal, vol. 5, 2008, pp. 315-327.

Loken, E. "Use of multicriteria decision analysis methods for energy planning problems." Renewable and Sustainable Energy Reviews, vol. 11, 2007, pp. 1584-1595.

MEMR. Ministry of Energy and Mineral Resources, Jordan, Annual Report, 2011.

Namrouqa, H., "King inaugurates Disi water project", in the Jordan Times, July 17, 2013. (Available at: http://jordantimes.com/king-inaugurates-disi-water-project)

Ramanathan, R. "Energy resource allocation inçorporating qualitative and quantitative criteria: an integrated model using goal programming and AHP." Socio-Economic Planning Science. vol. 29, 1995, pp. 197-218

Ray, P. "Staged climate change adaptation planning for water supply in Amman, Jordan." Journal of Water Resources Planning and Management, 2012, pp. 403-411. 
Rosenberg, D. "Modeling Integrated Water Utility Decisions with Recourse and Uncertainty: Amman, Jordan." Water Resources Management, vol. 23 2009, pp. 85-115.

Shami, S. "Parched Jordan faces water crises as Syrian refugees flood in", Thomson Reuters Foundation, 2013.

Siddiqi, A. Kajenthira, A., and Anadon, L. D. "Bridging decision networks for integrated water and energy planning", Energy Strategy Reviews, vol. 2, no. 1, 2013, pp. 46-58.

Siddiqi, A. and de Weck, O. L. "Quantifying End-Use Energy Intensity of the Urban Water Cycle", Journal of Infrastructure Systems, 2013 , pp 474-485.

Siddiqi, A. and Wescoat, J. L.2 "Energy use in large-scale irrigated agriculture in the Punjab province of Pakistan", Water International, 2013, pp. 571-586.

Thuesen, G. and Fabrycky, W. J. Engineering Economy (Ninth ed.), Prentice Hall, 2001.

Updated Master Strategy of Energy Sector in Jordan for the period (2007-2020), First Part. December 2007. 
TABLE I. STAKEHOLDERS IN JORDAN WATER SECTOR

\begin{tabular}{|l|l|}
\hline \multicolumn{1}{|c|}{ Category } & \multicolumn{1}{c|}{ Organizations } \\
\hline Former and & Ministries of: \\
Current Ministers,, & Energy \& Mineral \\
Secretary & Resources, \\
Generals, & Water \& Irrigation \\
Directors of & (MWI), \\
Planning & Environment, \\
& Industry \& Trade, \\
& Planning \& International \\
& Cooperation \\
\hline $\begin{array}{l}\text { Project } \\
\text { Management }\end{array}$ & MWI-PMU, \\
Units, & Mercy Corps \\
Nonprofit & \\
Organizations & \\
\hline $\begin{array}{l}\text { Farmers } \\
\text { Organizations, } \\
\text { Community } \\
\text { Organizations }\end{array}$ & Jordan Valley Farmers \\
\hline
\end{tabular}




\begin{tabular}{|c|c|c|c|c|c|}
\hline \# & $\mathrm{DM}^{\mathrm{a}}$ & $\mathrm{DM} 2^{\mathrm{a}}$ & $\mathrm{DM}^{\mathrm{b}}$ & $\mathrm{DM} 4^{\mathrm{c}}$ & $\mathrm{DM}^{\mathrm{c}}$ \\
\hline 1 & $\begin{array}{l}\text { Societal } \\
\text { Demand }\end{array}$ & $\begin{array}{l}\text { Cost, } \\
\text { Annual } \\
\text { Supply }\end{array}$ & $\begin{array}{c}\text { Political } \\
\text { Feasibility }\end{array}$ & Cost & Cost \\
\hline 2 & Cost & $\begin{array}{l}\text { Sectoral } \\
\text { Priorities }\end{array}$ & Cost & $\begin{array}{l}\text { Foreign } \\
\text { Invest. } \\
\text { Potential }\end{array}$ & $\begin{array}{c}\text { Foreign } \\
\text { Invest. } \\
\text { Potential }\end{array}$ \\
\hline 3 & $\begin{array}{c}\text { Political } \\
\text { Feasibility }\end{array}$ & $\begin{array}{c}\text { Geo. } \\
\text { Distrib. }\end{array}$ & $\begin{array}{l}\text { Annual } \\
\text { Supply }\end{array}$ & $\begin{array}{l}\text { Annual } \\
\text { Supply }\end{array}$ & $\begin{array}{l}\text { Annual } \\
\text { Supply }\end{array}$ \\
\hline 4 & $\begin{array}{c}\text { Foreign } \\
\text { Invest. } \\
\text { Potential }\end{array}$ & $\begin{array}{c}\text { Env. } \\
\text { Impact }\end{array}$ & $\begin{array}{l}\text { Env. } \\
\text { Impact }\end{array}$ & $\begin{array}{c}\text { Political } \\
\text { Feasibilit } \\
\text { y, Social } \\
\text { Priority, } \\
\text { Env. } \\
\text { Impact, } \\
\text { Supply } \\
\text { Sust. }\end{array}$ & $\begin{array}{l}\text { Political } \\
\text { Feasibility }\end{array}$ \\
\hline 5 & & $\begin{array}{c}\text { Resource } \\
\text { Sustainab- } \\
\text { ility }\end{array}$ & $\begin{array}{l}\text { Foreign } \\
\text { Invest. } \\
\text { Potential }\end{array}$ & & $\begin{array}{c}\text { Social } \\
\text { Priority }\end{array}$ \\
\hline 6 & & & $\begin{array}{c}\text { Socio- } \\
\text { Economic } \\
\text { Dev. }\end{array}$ & & $\begin{array}{l}\text { Harmful } \\
\text { Env. } \\
\text { Impacts }\end{array}$ \\
\hline 7 & & & & & $\begin{array}{l}\text { Supply } \\
\text { Sust. }\end{array}$ \\
\hline
\end{tabular}

${ }^{a}$ Ministry of Water and Irrigation

${ }^{\mathrm{b}}$ Ministry of Planning and International Cooperation

${ }^{c}$ Ministry of Environment 
TABLE III. WATER SUPPLY PROJECTS IN JORDAN

\begin{tabular}{|c|c|}
\hline Project & Project Description \\
\hline $\begin{array}{l}\text { Red-Dead } \\
\text { Conveyor } \\
(\mathrm{RDC})-\mathrm{A} 1\end{array}$ & $\begin{array}{l}\text { A project to transport water from the Red } \\
\text { sea to the Dead sea that would provide } \\
\text { desalinated water to Jordan and Israel and } \\
\text { replenish the Dead Sea that has been } \\
\text { affected by upstream water withdrawals. }\end{array}$ \\
\hline $\begin{array}{l}\text { Jordan Red } \\
\text { Sea Water } \\
\text { Project } \\
\text { (JRSP) - A2 }\end{array}$ & $\begin{array}{l}\text { This project is an advancing initiative } \\
\text { between Jordan, Israel and the Palestinian } \\
\text { Authority, in which private investors will } \\
\text { finance construction of a large } \\
\text { desalination plant on the Gulf of Aqaba in } \\
\text { Jordan. The desalinated water will be } \\
\text { shared by Jordan and Israel, and Israel } \\
\text { will increase water sales to the Palestinian } \\
\text { Authority. This is viewed as the first } \\
\text { phase of the larger RDC project }\end{array}$ \\
\hline $\begin{array}{c}\text { Aqaba } \\
\text { Desalination } \\
\text { Project } \\
\text { (ADP) - A3 }\end{array}$ & $\begin{array}{l}\text { This project is the construction of a large- } \\
\text { scale desalination plant at Aqaba with a } \\
\text { pipeline to provide freshwater to Amman. }\end{array}$ \\
\hline $\begin{array}{l}\text { Disi Aquifer } \\
\text { Pipeline } \\
\text { (DAP) - A4 }\end{array}$ & $\begin{array}{l}\text { A long-distance pipeline project that } \\
\text { would provide pumped groundwater from } \\
\text { the non-renewable Disi Aquifer, located } \\
\text { at the border between Jordan and Saudi } \\
\text { Arabia, to Amman. }\end{array}$ \\
\hline $\begin{array}{l}\text { Waste Water } \\
\text { Treatment } \\
\text { Expansion } \\
\text { (WWTE) - } \\
\text { A5 }\end{array}$ & $\begin{array}{l}\text { This project included wastewater network } \\
\text { reinforcement in the Zarqa governorate } \\
\text { and waste water treatment expansion of } \\
\text { the As-Samra waste water treatment plant } \\
\text { that serves Amman and Zarqa } \\
\text { governorates. }\end{array}$ \\
\hline
\end{tabular}


TABLE IV. DECISION CRITERIA FOR WATER SUPPLY PROJECTS IN JORDAN

\begin{tabular}{|c|c|c|c|c|c|c|}
\hline \multirow[b]{2}{*}{ Criteria } & \multirow[b]{2}{*}{$\begin{array}{l}\text { Obje } \\
\text { c-tive }\end{array}$} & \multicolumn{5}{|c|}{ Projects (alternatives) } \\
\hline & & $\begin{array}{l}\text { A1- } \\
\text { RDC }\end{array}$ & $\begin{array}{c}\text { A2 - } \\
\text { JRS } \\
P\end{array}$ & $\begin{array}{l}\text { A3- } \\
\text { AD }\end{array}$ & $\begin{array}{l}\text { A4- } \\
\text { DAP }\end{array}$ & $\begin{array}{c}\text { A5- } \\
\text { WWTE }\end{array}$ \\
\hline 1. Cost [B \$] & $\min$ & 10 & 2 & 1 & 1 & 0.151 \\
\hline $\begin{array}{l}\text { 2. Supply } \\
{\left[\mathrm{M} \mathrm{m}^{3} / \mathrm{yr}\right]}\end{array}$ & $\max$ & 1860 & 120 & 70 & 100 & 35.7 \\
\hline $\begin{array}{l}\text { 3.Political } \\
\text { Feasibility }\end{array}$ & $\max$ & Low & Med & High & High & High \\
\hline $\begin{array}{l}\text { 4.Foreign } \\
\text { Investment } \\
\text { Potential }\end{array}$ & $\max$ & Low & Med & Low & Med & High \\
\hline $\begin{array}{l}\text { 5.Env. } \\
\text { Sustainability }\end{array}$ & $\max$ & Med & Med & Med & Low & High \\
\hline
\end{tabular}

